Miami Nature Biotechnology Short Reports

TheScientificWorld (2001) 1 (S3), 142SR

ISSN 1532-2246; DOI 10.1100/tsw.2001.233

\title{
THE LATE INCREASE OF FREE RADICALS DURING GENOTOXIC-STRESS INDUCED APOPTOSIS IS ASSOCIATED WITH CYTOCHROME C RELEASE FROM MITOCHONDRIA INDUCED BY CASPASE-MEDIATED FEEDBACK LOOP AMPLIFICATION
}

\author{
Quan Chen (1,2), Yucheng Chai (3), Suparna Mazuder (1), Judy Drazba (5), \\ Guy Chisolm (3), and Alex Almasan (1,4,\#)
}

Department of Cancer Biology (1), Department of Cell Biology (3), Lerner Research Institute, and Department of Radiation Oncology (4), Department of Imaging Facility (5), The Cleveland Clinic Foundation, Cleveland, OH 44195; (2)The National Key Laboratory of Biomembrane and Membrane Biotechnology, Chinese Academy of Sciences, Beijing 100080, China

Release of cytochrome c (cyt c) from mitochondria is a critical event for the onset of apoptosis induced by death stimuli. We have described recently that cyt c was released in two distinct stages and that a positive feedback loop linked caspase activation to the late cyt c release and mitochondrial dysfunction during genotoxic stress-induced apoptosis (Cell Death and Differentiation (1999) 7(2), 227-233). We show here that there are also distinct levels of intracellular reactive oxygen species (ROS), namely hydrogen peroxide and superoxide anion, measured by CM-H2DCFDA and dehydroethidium staining as determined by flow cytometry following ionizing radiation (IR) in IM-9 cells. There was a small increase of ROS and glutathione consumption in both parental IM-9 and its derivative Bcl-2 over-expressing cells following IR. The late cellular ROS increase was associated with the cyt c depletion from mitochondria by caspase-mediated feedback amplification. We showed that the late ROS production and GSH depletion were inhibited by z-VAD-fmk and ectopic Bcl-2. U266, another multiple myeloma cell line which is resistant to radiation-induced apoptosis shows no increase of ROS following IR. Furthermore, over-expression of a dominant negative caspase-9 prevented IR-induced cell death, the increase of cellular ROS levels, and GSH depletion. While ectopic Bcl-2 prevents the late ROS production and depletion of GSH, endogenous Bcl2 could be targeted by caspases and its cleavage is associated with the late stage cyt c release and increase of cellular ROS, since over-expression of truncated Bcl-2 induces cyt c release, and consequently apoptosis. These results suggest that intracellular ROS production is associated with the late cyt $\mathrm{c}$ release and that $\mathrm{Bcl}-2$ truncation is a component of the amplification loop of caspase-mediated cyt c release and cellular ROS production. 

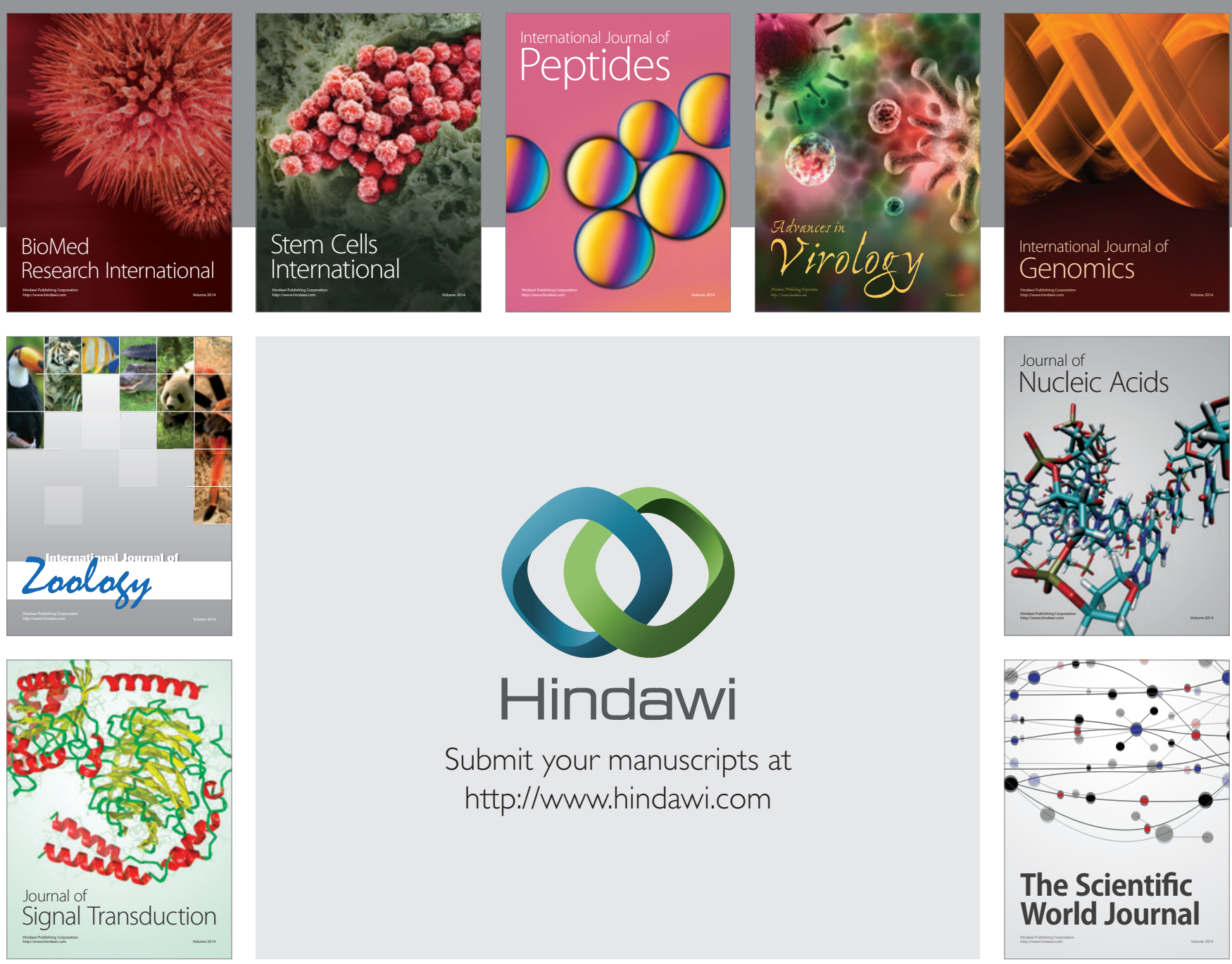

Submit your manuscripts at

http://www.hindawi.com
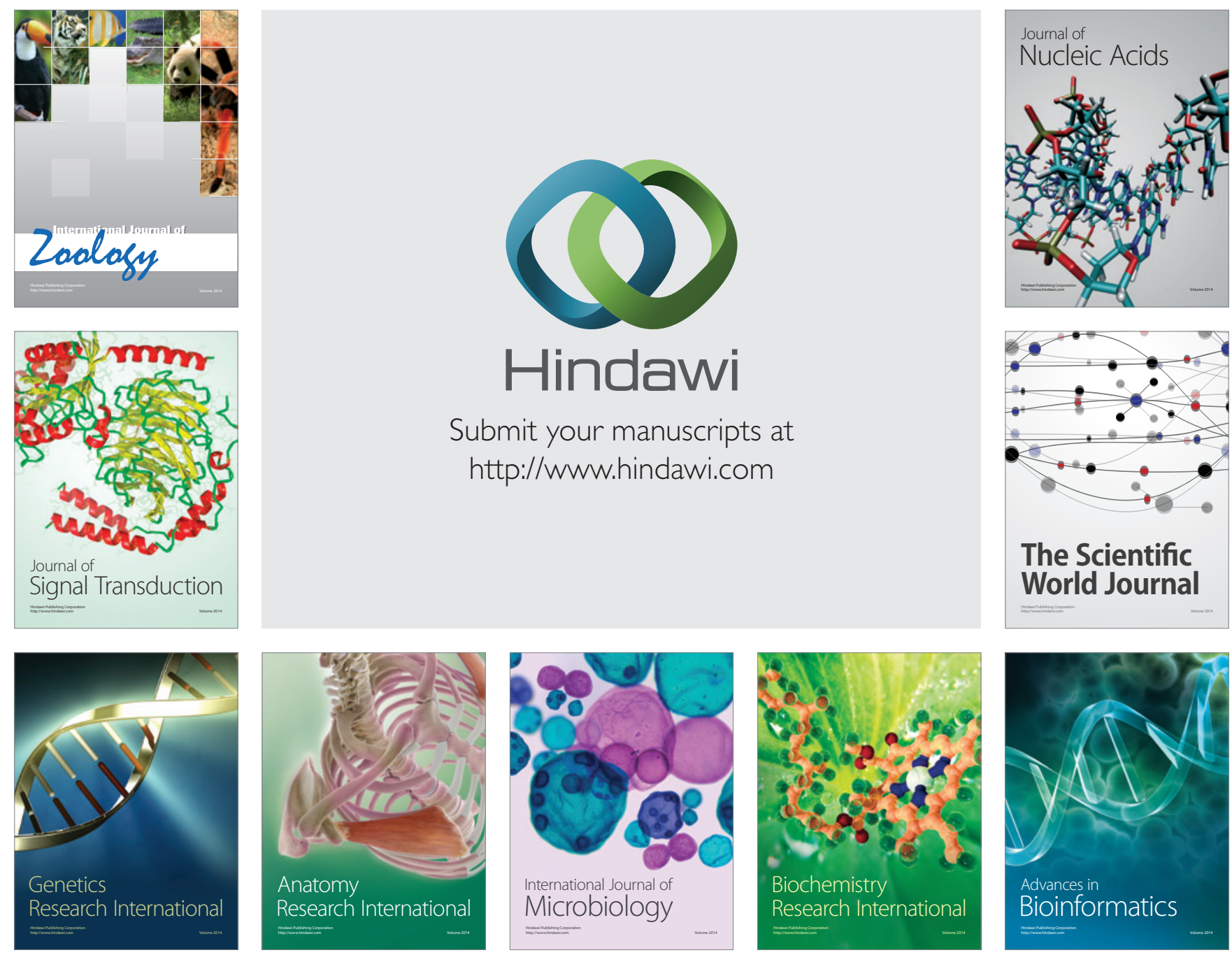

The Scientific World Journal
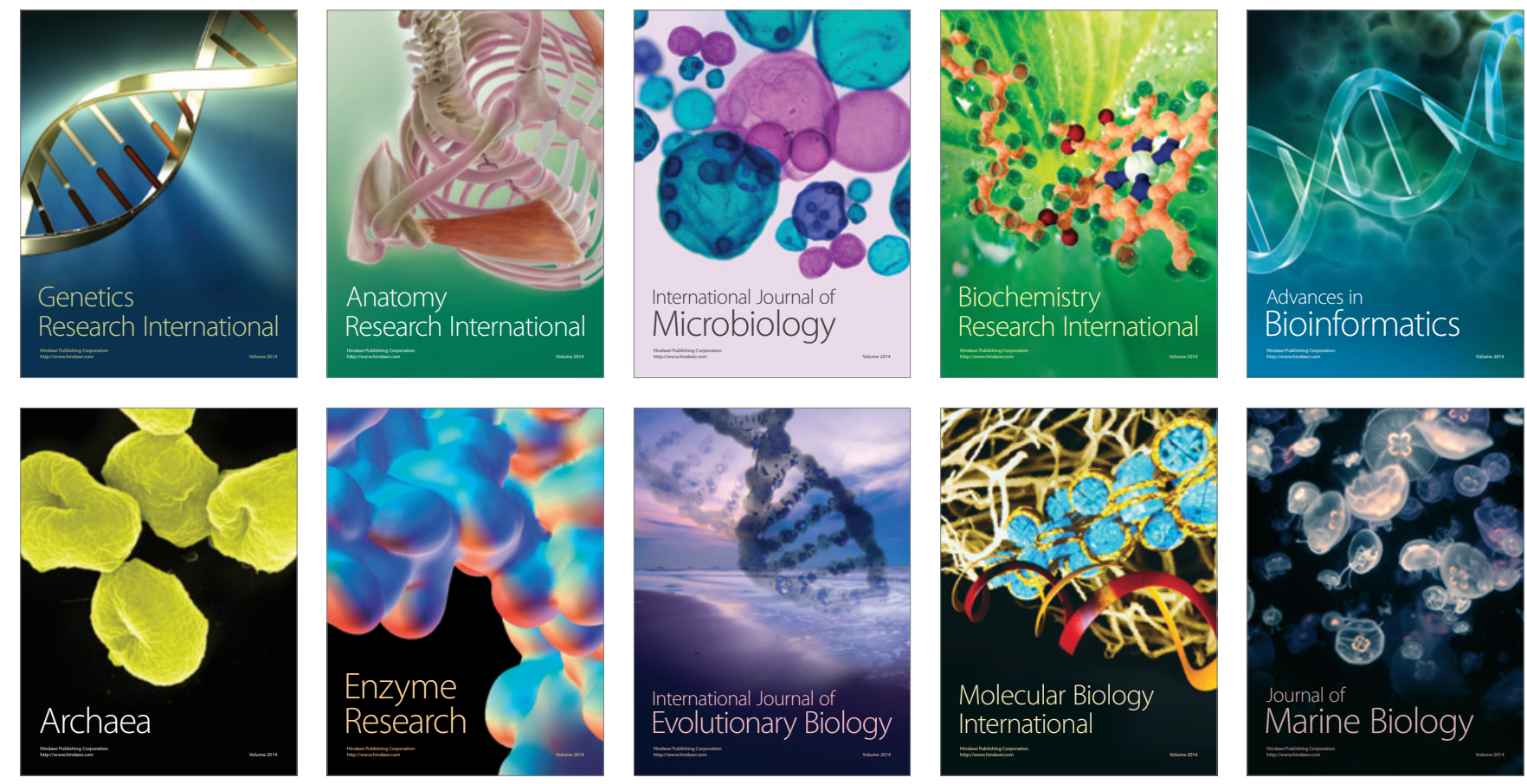